\title{
Parsing dan Konversi Kalimat Tanya Konfirmatif Menjadi Query Sparql Menggunakan Pendekatan Top-Down Parsing
}

\author{
Mohammad Syarief \\ Prodi Manajemen Informatika, Universitas Trunojoyo Madura \\ mohammad.syarief@trunojoyo.ac.id
}

\begin{abstract}
ABSTRAK
Penelitian ini merupakan lanjutan penelitian sebelumnya (Syarief, 2014), yaitu dengan menambahkan fitur pengenalan kalimat tanya konfirmasi, yaitu kalimat tanya yang hanya membutuhkan jawaban ya atau tidak. Data yang dibahas dalam peneltian ini menggunakan ontologi OntoMotif (Syarief, 2015) sebagai ontologi utama. Pendekatan teknik parsing yang digunakan adalah top-down parsing dengan menekankan pada pengenalan predikat. Penyusunan gramatika kalimat tanya konfirmatif dalam penelitian ini difokuskan pada pengenalan kalimat berita sederhana berbentuk SPO (subjek - predikat - objek) dengan 4 macam predikat utama, yaitu diproduksi, memproduksi, mempunyai, dan dimiliki. Dari hasil pengujian, dapat disimpulkan bahwa pendekatan teknik parsing dan konversi dalam penelitian ini berhasil menjawab pertanyaan yang cukup bervariasi seputar fitur-fitur kendaraan bermotor.

Kata Kunci: parsing, pengenalan kalimat, kalimat tanya konfirmatif, query sparql, top-down parsing, pengenalan predikat.

\section{PARSING AND CONVERSION OF YES-NO QUESTION INTO SPARQL QUERY USING TOP-DOWN PARSING APPROACH}

\section{ABSTRACT}

This paper is a continuation of our previous paper (Syarief, 2014), by adding a feature of yes-no questions (interrogative sentences that only requires a yes or no answer) recognition. The data use OntoMotif (Syarief, 2015) as main ontology. Parsing technique approach used in this paper is top-down parsing. This approach is developed based on predicate-argument recognition of a simple sentence. The grammar focused on recognition of a simple SPO (subject predicate - object) sentences with 4 main predicates, i.e diproduksi (manufactured), memproduksi (produced), mempunyai (have), and dimiliki (owned). Based on test results, it can be concluded that the this approach managed to answer varied questions around otomotives and their features.

Keywords: parsing, sentence recognition, yes-no question, sparql query, topdown parsing, predicate-argument recognition. 


\section{PENDAHULUAN}

Transportasi merupakan bagian hidup yang tak terpisahkan dari kehidupan manusia, maka informasi mengenai kendaraan bermotor sebagai sarana transportasi tentu juga sangat diperlukan. Pada era digital ini, pencarian informasi biasanya dilakukan dengan internet sebagai media utamanya.

Salah satu alternatif pencarian informasi yang lebih terarah dari pada mesin pencari adalah sistem tanya jawab. Mesin pencari akan memberikan alternatifalternatif jawaban dengan menyertakan link-link terkait, sedangkan sistem tanya jawab akan langsung memberikan jawaban dari pertanyaan yang diajukan (Cody Kwok, 2001).

\section{Implementasi sistem tanya jawab mengharuskan adanya pemahaman terhadap kalimat input dalam rangka memberikan jawaban yang tepat sesuai yang diinginkan oleh penanya. Penelitian-penelitian tentang pengenalan kalimat berbahasa Indonesia sudah banyak dilakukan, diantaranya pengenalan kalimat tanya yang mengandung unsur perbandingan (Bendi, 2009). Selain itu, pemrosesan kalimat kompleks dan kreatif juga telah dikembangkan oleh (Larasati, 2007; Mahendra, 2008; Suryawan, 2013).}

Penggunaan kata umum dalam pencarian sering kali menjadi sebab pencarian kurang terarah. Contohnya pencarian dengan kata kunci (kalimat) "Adakah kendaraan yang berkarburasi injeksi" akan menyebabkan hasil pencarian yang kurang valid jika sistem tidak dapat mendeteksi bahwa Mio, Vario, dan semisalnya termasuk kategori motor, dan motor merupakan salah satu jenis kendaraan. Salah satu cara mengatasi hal tersebut adalah dengan menggunakan teknologi Web Semantik (Berners-Lee, 2001).

Penggunaan teknologi web semantik menggunakan sistem tanya jawab pada domian otomotif (SiTaSO) sudah dikembangkan sebelumnya (Syarief, 2014). Namun, SiTaSO hanya dapat menjawab pertanyaan yang menggunakan kata tanya apa, berapa, dan dimana. Dalam pendekatan pengenalan kalimatnya, SiTASO menggunakan pendekatan pengenalan predikat. Predikat-predikat yang dapat dikenali dibatasi dengan diproduksi, memproduksi, mempunyai, dimiliki, dijual, menjual, menyewakan, dan disewakan.

Penelitian ini merupakan
lanjutan penelitian sebelumnya (Syarief, 2014), yaitu dengan menambahkan fitur pengenalan kalimat tanya konfirmasi, yaitu kalimat tanya yang hanya membutuhkan jawaban ya atau tidak (yes-no question). Data yang dibahas dalam peneltian ini menggunakan ontologi OntoMotif (Syarief, 2015)

\section{METODE PENELITIAN}

Penelitian ini membahas tentang bagaimana cara mengenali kalimat tanya konfirmatif dan mentransformasikan pemahaman kalimat itu menjadi bentuk query SPARQL. Kombinasi kalimat tanya konfirmatif berbahasa Indonesia sangatlah banyak. Oleh karena itu, untuk memfokuskan pembahasan, maka dilakukan pembatasan topik dan gramatika kalimat tanya. Topik yang dibahas dalam penelitian kali ini adalah pertanyaan konfirmatif tentang fitur-fitur kendaraan bermotor. 


\section{Penyusunan gramatika kalimat}

Tabel 1. Daftar predikat

\begin{tabular}{ll}
\hline Predikat Utama & Ekuivalensi \\
\hline Diproduksi & Dibuat \\
& dikeluarkan \\
Memproduksi & Membuat \\
& mengeluarkan \\
Mempunyai & Memiliki \\
& Ber- (prefiks) \\
Dimiliki & menggunakan \\
& Dipunyai \\
& Digunakan \\
& Terdapat pada/di \\
\hline
\end{tabular}

Tabel 2.

\begin{tabular}{cll}
\hline Penanda & \multicolumn{1}{c}{ Nama Tanda } & \multicolumn{1}{c}{ Keterangan } \\
\hline$<>$ & Tanda kurung sudut & $\begin{array}{l}\text { kata yang berada diantara tanda ini } \\
\text { menunjukkan bahwa kata itu adahah } \\
\text { sebuah variable } \\
\text { keberadaan kata yang berada diantara } \\
\text { ( ) } \quad \begin{array}{l}\text { Tanda kurung menunjukan sifat } \\
\text { lengkung }\end{array} \\
\text { opsional; boleh ada atau tidak ada } \\
\text { Tanda kurung siku- } \\
\text { siku }\end{array}$ \\
& $\begin{array}{l}\text { Keberadaan beberapa tanda ini dalam } \\
\text { kalimat menunjukan posisinya yang } \\
\text { saling bisa dipertukarkan dan juga } \\
\text { bersifat opsional dengan ketentuan } \\
\text { minimal terdapat sebuah dalam kalimat }\end{array}$ \\
\hline
\end{tabular}

Proses penyusunan gramatika kalimat tanya konfirmatif dalam penelitian ini difokuskan pada pengenalan kalimat sederhana berbentuk SPO (subjek - predikat objek). Standar tata bahasa yang digunakan mengacu pada Tata Bahasa Baku Bahasa Indonesia $(\mathrm{H}$. Alwi, 2003). Dalam topik pengenalan pertanyaan konfirmatif tentang fiturfitur kendaraan bermotor, ternyata kombinasi predikat utama (secara makna) tidak terlalu banyak. Maka untuk menyederhanakan proses penyusunan gramatika, dilakukan pemetaan antara predikat utama dengan setaranya. Daftar predikat utama dan ekuivalensinya ditunjukkan padat Tabel 1.

Beberapa penanda yang perlu diketahui dalam memahami pola kalimat dalam penyusunan grammar kalimat disebutkan dalam Tabel 2.

Dengan memperhatikan penanda-penanda yang telah dijelaskan pada tabel 2, maka dibuatlah gramatika kombinasi kalimat berita dengan beberapa predikat, seperti tampak pada Gambar 1,2,3,4,5. 


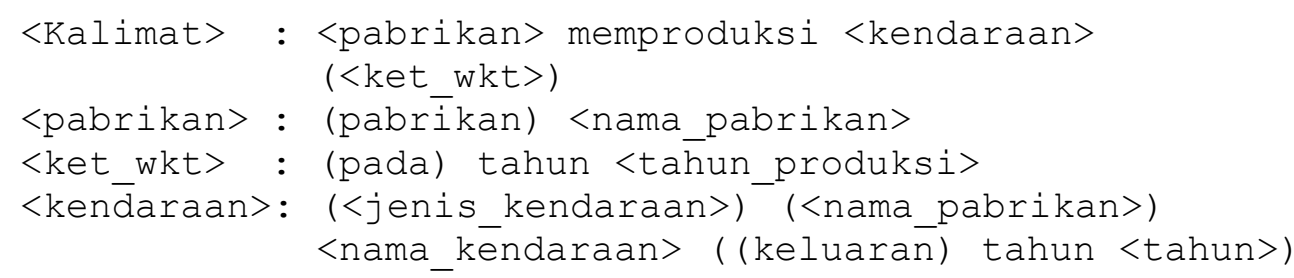

Gambar 1. Gramatika kalimat berita dengan predikat: diproduksi

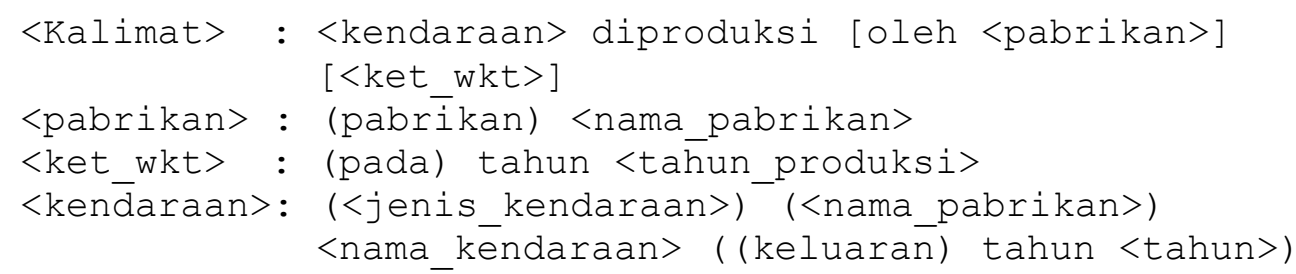

Gambar 2. Gramatika kalimat berita dengan predikat: memproduksi

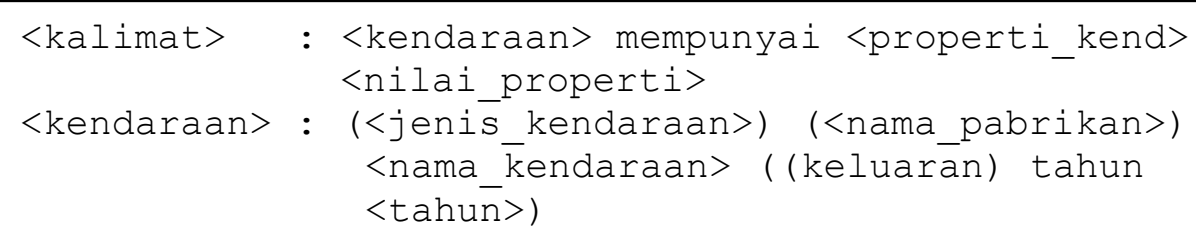

Gambar 3. Gramatika kalimat berita dengan predikat: mempunyai

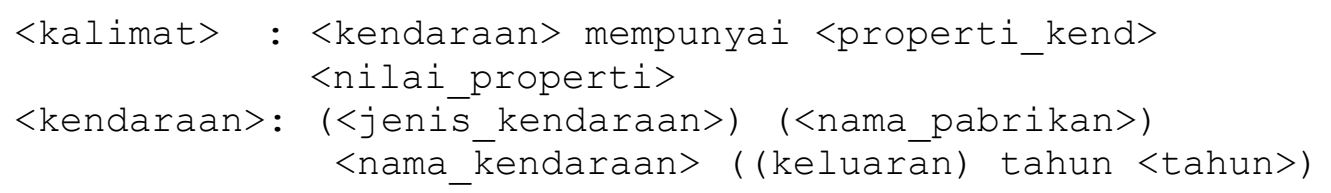

Gambar 4. Gramatika kalimat berita dengan predikat: dimiliki

Untuk mengubah kalimat berita yang dijelaskan gramatikanya pada Gambar 1 menjadi kalimat tanya adalah dengan menambahkan kata tanya Apakah di awal kalimat, atau menambah kata kan atau bukan di akihir kalimat.

\section{Parsing dan Konversi}

Pemrosesan bahasa alami (parsing) dalam penelitian ini mempunyai tujuan untuk mengecek grammar kalimat input, sedangkan konversi bertujuan untuk menguraikan kalimat tanya menjadi formulasi query SPARQL. Untuk mewujudkan tujuan tersebut, digunakan pendekatan top-down parsing. Dalam implementasinya, parser bertumpu pada pengenalan predikat kalimat sederhana. Tahaptahapan proses yang digunakan dalam pendekatan ini digambarkan dalam bentuk flowchart, seperti yang ditunjukkan dalam Gambar 5. 


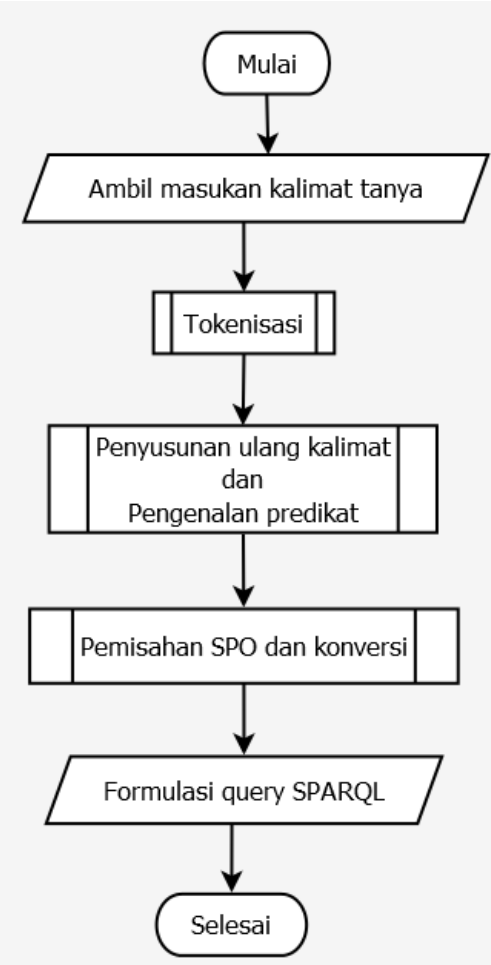

Gambar 5. Diagram alir gambaran umum parsing

\section{Tokenisasi}

Tokenisasi

yang

dimaksudkan di sini adalah proses pemecahan kalimat tanya menjadi himpunan frasa/kata yang dianggap penting.

\section{Penyusunan ulang kalimat dan pengenalan predikat}

Tujuan dari proses ini adalah untuk meminimalkan kombinasi pola kalimat dalam rangka mempermudah proses konversi dan mendata daftar predikat utama yang ada dalam kalimat dan posisinya dalam kalimat tanya input.

\section{Pemisahan SPO dan konversi}

Proses ini merupakan proses utama dalam program parsing. Tujuannya adalah untuk memetakan kalimat tanya input menjadi pola SPO, kemudian memproses pola SPO tersebut sesuai dengan predikat utamanya. Pemetaan kalimat menjadi himpunan SPO dimaksudkan untuk memudahkan dalam konversi kalimat menjadi formulasi query SPARQL, sebab pernyataan dalam web semantik selalu berupa triple (resource properti - nilaiProperti) yang serupa dengan pola SPO.

\section{HASIL DAN PEMBAHASAN}

Dalam rangka mengecek keberhasilan penelitian ini, maka perlu dilakukan pengujian. Pengujian dilakukan menggunakan SiTASO (Syarief, 2014) sebagai lingkungan kerja dan OntoMotif (Syarief, 2015) sebagai ontologi utama. Prosedur dalam pengujian ini adalah dengan menginputkan kalimat tanya konfirmatif ke dalam SiTaSO, seperti yang ditunjukkan dalam Gambar 6. 
Pertanyaan: apakah honda blade mempunyai harga 1400000

Tanya

Pertanyaan: apakah honda blade mempunyai harga 14000000

ASR

f

?blade ok:diproduksioleh ?honda .

?honda a ok:Honda.

?blade ok: nama ?namal.

?produk ok:hargaJual ?propertil.

?produk ok:deskripsi ?blade.

?propertil rdf:value ?nilai_propertil.

?properti1 ok:tipeSatuan ?satuan1.

FILTER (regex(?nama1, "blade", "i") \&\& ?nilai_properti1 = 14000000)

\}

Jawaban:

Ya

Gambar 6. Contoh pengujian parsing dan konversi menggunakan SiTaSO

Berikut akan diberikan beberapa contoh hasil konversi sesuai dengan predikat utamanya:

\section{Jazz R5 diproduksi oleh honda, kan?}

ASK

?jazz_r5 ok:nama ?nama1.

?jazz_r5 ok:diproduksioleh ?honda.

?honda ok:nama ?nama pabrikan1.

FILTER (regex(?namal, "jazz", "i") \&\& regex(?nama1,

"r5", "i") \&\& regex(?nama_pabrikan1, "honda", "i"))

\section{honda memproduksi Accord VTI, bukan?}

ASK

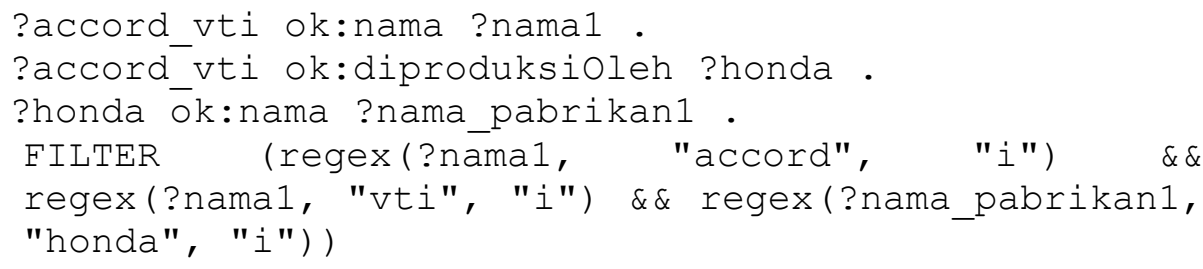


adakah supra yang menggunakan karburasi injeksi?

ASK

?supra ok:nama ?nama1.

?supra ok:sistemKarburasi ?propertil.

?propertil ok:nama ?nilai_propertil.

FILTER (regex(?nama1, "supra", "i") \&\&

regex(?nilai_propertil, "injeksi", "i"))

\}

apakah honda blade mempunyai harga 14000000

A.SK

?blade ok:diproduksioleh ?honda.

?honda a ok:Honda .

?blade ok:nama ?namal.

?produk ok:hargaJual ?propertil.

?produk ok:deskripsi ?blade.

?propertil rdf:value ?nilai propertil.

?propertil ok:tipeSatuan ?satuan1.

FILTER (regex(?nama1, "blade", "i") \&\&

?nilai_propertil $=14000000)$

\}

apakah motor honda supra x keluaran tahun 2015 berkarburasi injeksi

ASK

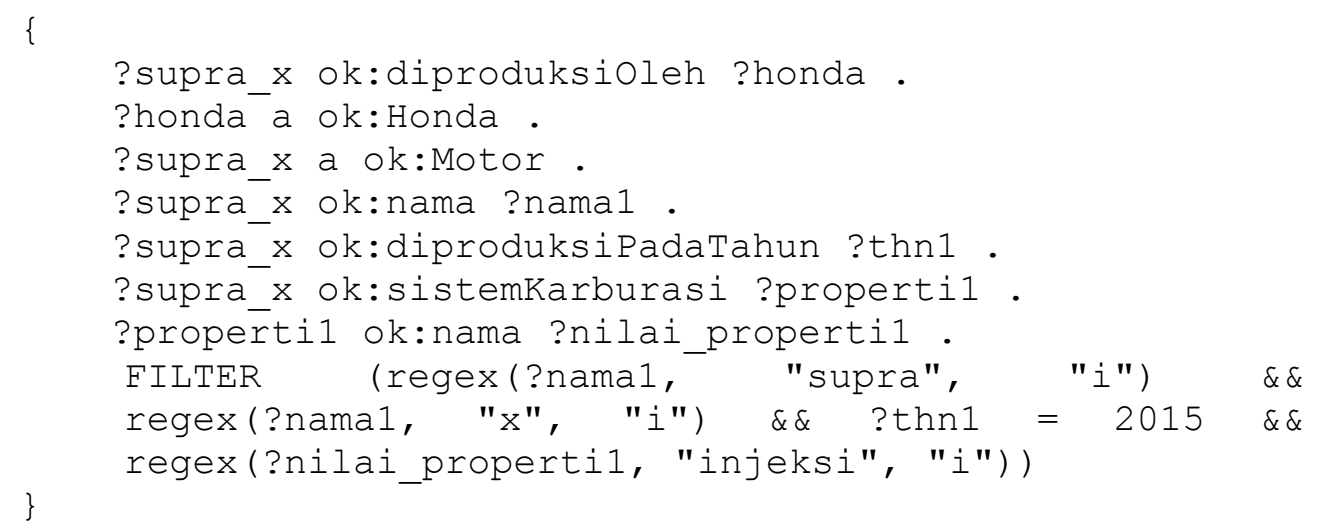

apakah rem depan cakram terdapat pada supra $x$ tahun 2013?

ASK

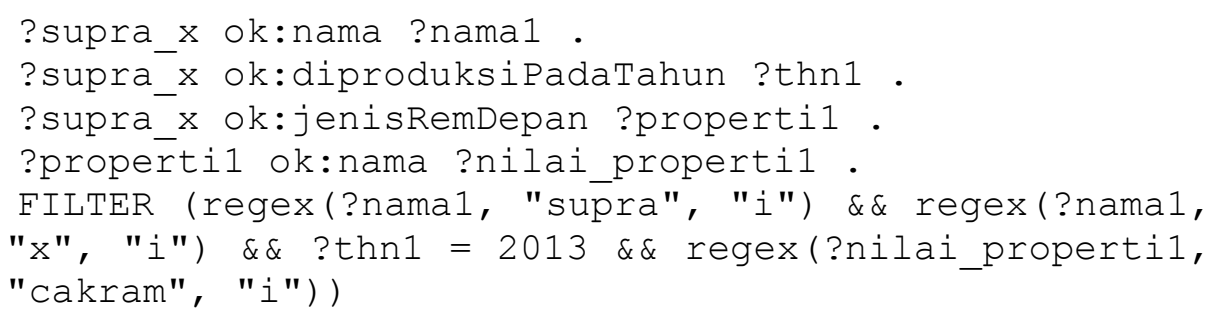




\section{SIMPULAN DAN REKOMENDASI}

Dari hasil pengujian, dapat disimpulkan bahwa pendekatan teknik parsing dan konversi dalam penelitian ini berhasil menjawab pertanyaan yang cukup bervariasi berupa kalimat sederhana seputar fitur-fitur kendaraan bermotor. Dalam

\section{DAFTAR PUSTAKA}

Bendi, R. K. (2009). Sistem Question Answering Sederhana Berbasis Ontologi sebagai Aplikasi Web Semantik. Yogyakarta: FMIPA UGM.

Berners-Lee, T. H. (2001). The Semantic Web. Scientific American, 284(5), 34-43.

Cody Kwok, O. E. (2001). Scaling question answering to the web. ACM Transactions on Information Systems (TOIS), 19(3), 242-262.

H. Alwi, S. D. (2003). Tata Bahasa Baku Bahasa Indonesia. Jakarta: Balai Pustaka.

Rahmad Mahendra, S. D. (2008). Extending an Indonesian Semantic Analysis-based Question Answering System with Linguistic and World Knowledge Axioms.

Proceedings of the 22nd Pacific Asia Conference on Language, Information, and Computation. penegembangan berikutnya, disarankan untuk melengkapi keterbatasan dalam penelitian ini, yaitu dengan cara menambahkan fitur pengenalan kalimat tanya yang mengandung unsur perbandingan fitur kendaraan dan kalimat tanya kompleks.

Septina Dian Larasati, R. M. (2007). Towards a semantic analysis of bahasa Indonesia for question answering. Proceedings of the 10th Conference of the Pacific Association for Computational Linguistics, (pp. 273--280).

Suryawan, I. W. (2013). Sistem Question Answering Menggunakan Pendekatan Berbasis Pengetahuan. Yogyakarta: FMIPA UGM.

Syarief, M. (2014). Implementasi Parsing Kalimat Bahasa Indonesia berdasarkan Pengenalan Predikat pada Sistem Tanya Jawab dengan Teknologi Web Semantik. Yogyakarta: FMIPA UGM.

Syarief, M. (2015). OntoMotif: Ontologi Pencarian Informasi Kendaraan Bermotor. Semnastek 2015 (pp. 1-10). Jakarta: Semnastek. 